\title{
Synthesis and in vitro cholesterol dissolution by 23- and 24-phosphonobile acids
}

\author{
Ponnusamy Babu, Uday Maitra* \\ Department of Organic Chemistry, Indian Institute of Science, Bangalore 560012, India
}

\begin{abstract}
A new class of 23- and 24-phosphonobile acids have been synthesized from bile acid and their in vitro cholesterol-dissolving efficiency have been estimated. 24-Phosphonobile salts (PBSs) are slightly more efficient in solubilizing cholesterol than 23-PBSs and natural bile salts. The cholesterol solubilizing power is influenced by the structure of PBSs, and is considerably reduced with an increase in the bulk pH.
\end{abstract}

Keywords: Bile acids; Cholesterol dissolution; Gallstone dissolution; Phosphonobile acids

\section{Introduction}

Bile acids, which are essential for many physiological functions, are end-products of cholesterol metabolism. The physiological functions of bile salts result from their interesting physico-chemical properties, which have been studied extensively [1]. The glycine/taurine conjugates of bile acids form mixed micelles with phospholipids $[2,3]$, which solubilizes cholesterol. Impeding this function may cause the over saturation of cholesterol in the bile leading to its precipitation. The accumulation of cholesterol micro-crystals in the presence of glycoproteins leads to gallstone formation or cholelithiasis [4]. Chenodeoxy [5] and ursodeoxycholic acids [6] have been used with success for the dissolution of cholesterol gallstones. Two of the limitations of bile acid therapy are: (a) they undergo 7-dehydroxylation giving rise to hepatotoxic lithocholic acid and (b) low efficacy and prolonged treatment periods.

Abbreviations: PBS, phosphonobile salt; PC, phosphonocholate; PCDC, phosphonochenodeoxycholate; PDC, phosphonodeoxycholate; PLC, phosphonolithocholate; PUDC, phosphonoursodeoxycholate

* Corresponding author at: Chemical Biology Unit, Jawaharlal Nehru Centre for Advanced Scientific Research, Bangalore 560012, India. Tel.: +91 80 2360 1968; fax: +91 8023600529.

E-mail address: maitra@orgchem.iisc.ernet.in (U. Maitra).
There is growing interest in recent years to find a better gallstone-dissolving agent, which would be resistant to 7-dehydroxylation. The design of a few synthetic analogs of bile acids described in the literature has addressed this issue. $\mathrm{N}$-methylated (sarcosine) glycocholate has been shown to possess therapeutic value, and is resistant to deconjugation and dehydroxylation [7]. The 7-methylated chenodeoxy and ursodeoxy derivatives were shown to be completely resistant to 7-dehydroxylation in hamsters [8]. Sulfonobile salts, side chain-modified analogs of natural bile salts, are resistant to 7-dehydroxylation, and do not interfere with endogenous bile acid synthesis $[9,10]$. We have recently reported the synthesis of novel 23-phosphonobile acids [11]. In this paper, we report the synthesis of new 23- and 24-phosphonobile acids and a study of their in vitro cholesterol solubilizing efficiency as a model study for gallstone dissolution.

\section{Experimental}

\subsection{Materials and methods}

Cholic, deoxycholic, chenodeoxycholic and lithocholic acids were purchased from Aldrich and were used as such. Ursodeoxycholic acid was also a commercial sample. Precoated silica gel glass plates with UV indicator on $(0.25 \mathrm{~mm}$ thick- 
ness, Sigma-Aldrich) were used for thin layer chromatography and Liebermann-Burchard reagent was used as the spray reagent to visualize the steroids. Acme 100-200 mesh silica gel was used for gravity column chromatography. All the solvents used were of laboratory grade and distilled prior to use. Dichloromethane and carbon tetrachloride were dried over $\mathrm{CaH}_{2}$. Melting points were recorded in Buchi B-540 melting point instrument. All optical rotation values were recorded on Jasco-DIP-370 polarimeter at $25^{\circ} \mathrm{C}$. Infrared spectra were recorded on a Jasco-70 FTIR spectrometer. Proton and carbon NMR spectra were recorded on a Jeol Lambda $300 \mathrm{MHz}$ and Bruker AMX $400 \mathrm{MHz}$ spectrometers. Phosphorous NMR was recorded on a Bruker AMX $400 \mathrm{MHz}$ spectrometer.

\subsubsection{A general procedure for the synthesis of formylated bile acids}

Formic acid $(20 \mathrm{~mL}, 517.4 \mathrm{mmol})$ was added to bile acid $(12.7 \mathrm{mmol})$ and stirred at $55^{\circ} \mathrm{C}$ for $20 \mathrm{~h}$. Volatiles were removed under reduced pressure. The free flowing solid was crystallized from EtOH/ $\mathrm{H}_{2} \mathrm{O}(1: 1.3, \mathrm{v} / \mathrm{v})$ and dried to give formylated bile acids [12].

2.1.1.1. $3 \alpha, 7 \alpha, 12 \alpha$-triformyloxy-5 $\beta$-cholan-24-oic acid. Yield 82\%; mp: 202-204 ${ }^{\circ} \mathrm{C}$; ${ }^{1} \mathrm{H} \mathrm{NMR}\left(300 \mathrm{MHz}, \mathrm{CDCl}_{3}\right) \delta$ : 8.165 (s, 1H), 8.11 (s, 1H), 8.02 (s, 1H), 5.27 (bs, 1H), 5.07 (bs, 1H), $4.76(\mathrm{~m}, 1 \mathrm{H}), 2.44-1.27(\mathrm{~m}), 1.18-1.05(\mathrm{~m}, 2 \mathrm{H})$, 0.94 (s, 3H), 0.85 (d, J=6.6 Hz, 3H), 0.76 (s, 3H); ${ }^{13} \mathrm{C} \mathrm{NMR}$ $\left(75 \mathrm{MHz}, \mathrm{CDCl}_{3}\right) \delta: 179.78,160.59,160.50,75.24,73.72$, 70.66, 47.18, 44.99, 42.94, 40.76, 37.69, 34.68, 34.49, 34.41, $34.25,31.30,30.80,30.37,28.52,27.12,26.54,25.51,22.74$, $22.31,17.42,12.12$.

2.1.1.2. $3 \alpha, 12 \alpha$-diformyloxy-5 $\beta$-cholan-24-oic acid. Yield 89\%; mp: $189-192{ }^{\circ} \mathrm{C} ;{ }^{1} \mathrm{H}$ NMR $\left(300 \mathrm{MHz}, \mathrm{CDCl}_{3}\right) \delta: 8.11$ $(\mathrm{s}, 1 \mathrm{H}), 8.01(\mathrm{~s}, 1 \mathrm{H}), 5.23(\mathrm{~s}, 1 \mathrm{H}), 4.81(\mathrm{~m}, 1 \mathrm{H}), 2.36(\mathrm{~m}, 1 \mathrm{H})$, $1.92-0.97(\mathrm{~m}), 0.90(\mathrm{~s}, 3 \mathrm{H}), 0.82(\mathrm{~d}, J=6.0 \mathrm{~Hz}, 3 \mathrm{H}), 0.73(\mathrm{~s}$, $3 \mathrm{H}) ;{ }^{13} \mathrm{C} \mathrm{NMR}\left(75 \mathrm{MHz}, \mathrm{CDCl}_{3}\right) \delta: 180.18,160.67,160.53$, 75.91, 74.04, 49.18, 47.28, 44.93, 41.65, 35.52, 34.70, 34.58, $34.12,33.94,32.01,30.89,30.40,27.27,26.70,26.39,25.83$, $25.66,25.36,22.86,17.36,12.26$.

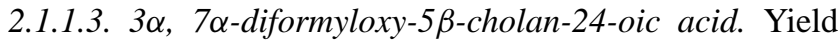
95\%; mp: $184-185{ }^{\circ} \mathrm{C} ;{ }^{1} \mathrm{H} \mathrm{NMR}\left(400 \mathrm{MHz}, \mathrm{CDCl}_{3}\right) \delta: 8.06$ $(\mathrm{s}, 1 \mathrm{H}), 8.01(\mathrm{~s}, 1 \mathrm{H}), 5.02(\mathrm{~s}, 1 \mathrm{H}), 4.74-4.69(\mathrm{~m}, 1 \mathrm{H})$, 2.41-2.33 (m, 1H), 2.28-2.10 (m, 1H), 2.0-1.1 (m), 0.93 $(\mathrm{s}, 3 \mathrm{H}), 0.92(\mathrm{~d}, J=6.0 \mathrm{~Hz}, 3 \mathrm{H}), 0.64(\mathrm{~s}, 3 \mathrm{H}) ;{ }^{13} \mathrm{C} \mathrm{NMR}$ $\left(100 \mathrm{MHz}, \mathrm{CDCl}_{3}\right) \delta: 179.93,160.73,74.07,71.42,55.78$, 50.14, 42.75, 41.04, 39.46, 37.96, 35.24, 34.81, 34.62, 34.03, $31.51,30.96,30.73,27.93,26.77,23.49,22.64,20.65,18.27$, 11.74 .

2.1.1.4. $3 \alpha$, 7 $\beta$-diformyloxy-5 $\beta$-cholan-24-oic acid. Yield 96\%; mp: $170-171{ }^{\circ} \mathrm{C} ;{ }^{1} \mathrm{H} \mathrm{NMR}\left(400 \mathrm{MHz}, \mathrm{CDCl}_{3}\right) \delta: 8.00$ (s, 1H), $7.96(\mathrm{~s}, 1 \mathrm{H}), 4.92-4.85(\mathrm{~m}, 1 \mathrm{H}), 4.83-4.75(\mathrm{~m}, 1 \mathrm{H})$, 2.41-2.33 (m, 1H), 2.27-2.19 (m, 1H), 1.86-1.0 (m), 0.97 $(\mathrm{s}, 3 \mathrm{H}), 0.91(\mathrm{~d}, J=6.4 \mathrm{~Hz}, 3 \mathrm{H}), 0.67(\mathrm{~s}, 3 \mathrm{H}) ;{ }^{13} \mathrm{C} \mathrm{NMR}$ $\left(100 \mathrm{MHz}, \mathrm{CDCl}_{3}\right) \delta: 179.90,161.00,160.61,73.69,73.44$, 53.37, 55.04, 43.68, 42.11, 39.91, 39.50, 35.17, 34.42, 34.00, $32.92,32.82,31.03,30.76,28.30,26.42,25.84,23.20,21.26$, 18.36, 12.09 .

2.1.1.5. 3 $\alpha$-Formyloxy-5 $\beta$-cholan-24-oic acid. Yield 95\%; mp: ${ }^{136}-138{ }^{\circ} \mathrm{C} ;{ }^{1} \mathrm{H}$ NMR $\left(300 \mathrm{MHz}, \mathrm{CDCl}_{3}\right) \delta: 8.03$ (s, $1 \mathrm{H}), 4.88-4.81(\mathrm{~m}, 1 \mathrm{H}), 2.44-2.19(\mathrm{~m}, 2 \mathrm{H}), 1.98-0.99(\mathrm{~m})$, $0.93(\mathrm{~s}, 3 \mathrm{H}), 0.92(\mathrm{~d}, J=6.6 \mathrm{~Hz}, 3 \mathrm{H}), 0.64(\mathrm{~s}, 3 \mathrm{H}) ;{ }^{13} \mathrm{C} \mathrm{NMR}$ $\left(75 \mathrm{MHz}, \mathrm{CDCl}_{3}\right) \delta: 180.29,160.84,74.42,56.43,55.92$, 42.72, 41.88, 40.42, 40.09, 35.76, 35.28, 34.94, 34.55, 32.18, $30.98,30.73,28.14,26.95,26.61,26.28,24.15,23.29,20.82$, $18.22,12.03$.

\subsubsection{General procedure for the synthesis of 24-hydroxy bile alcohols}

The formylated bile acid $(2.26 \mathrm{mmol})$ was dissolved in $\mathrm{THF}(8 \mathrm{~mL})$. To this solution, triethylamine $(0.4 \mathrm{~mL}$, $2.9 \mathrm{mmol}$ ) was added, followed by the dropwise addition of ethyl chloroformate $(0.28 \mathrm{~mL}, 2.92 \mathrm{mmol})$. After stirring for $2 \mathrm{~h}$, the reaction mixture was cooled with ice bath then added $\mathrm{NaBH}_{4}(0.4 \mathrm{~g})$ and methanol $(10 \mathrm{~mL})$ dropwise. After stirring at $0^{\circ} \mathrm{C}$ for $15 \mathrm{~min}$, the reaction mixture was stirred at $\mathrm{rt}$ for another $15 \mathrm{~min}$, diluted with water $(20 \mathrm{~mL})$, acidified with $0.2 \mathrm{M} \mathrm{HCl}(10 \mathrm{~mL})$, extracted with ethyl acetate $(3 \times 25 \mathrm{~mL})$, washed with water and dried over anhyd. $\mathrm{Na}_{2} \mathrm{SO}_{4}$. The crudeproduct was purified on a silica gel column using EtOAc/pet. ether (35-50:65-50, v/v).

2.1.2.1. $3 \alpha, 7 \alpha, 12 \alpha$-triformyloxy-5 $\beta$-24-hydroxy-cholane. Yield 77\%; ${ }^{1} \mathrm{H}$ NMR $\left(300 \mathrm{MHz}, \mathrm{CDCl}_{3}\right) \delta: 8.17(\mathrm{~s}, 1 \mathrm{H}), 8.10$ $(\mathrm{s}, 1 \mathrm{H}), 8.02(\mathrm{~s}, 1 \mathrm{H}), 5.27(\mathrm{~s}, 1 \mathrm{H}), 5.07(\mathrm{~s}, 1 \mathrm{H}), 4.71(\mathrm{~m}, 1 \mathrm{H})$, $3.61(\mathrm{~m}, 2 \mathrm{H}), 2.18-1.0(\mathrm{~m}), 0.94(\mathrm{~s}, 3 \mathrm{H}), 0.85(\mathrm{~d}, J=6.3 \mathrm{~Hz}$, $3 \mathrm{H}), 0.75(\mathrm{~s}, 3 \mathrm{H}) ;{ }^{13} \mathrm{C} \mathrm{NMR}\left(100 \mathrm{MHz}, \mathrm{CDCl}_{3}\right) \delta: 160.53$, 75.44, 73.79, 70.76, 63.37, 47.46, 45.05, 43.03, 40.90, 37.84, $35.04,34.58,34.34,31.65,31.41,29.33,28.63,27.30,26.64$, 25.61, 22.83, 22.35, 17.87, 12.62 .

2.1.2.2. $3 \alpha, 12 \alpha$-diformyloxy-5 $\beta$-24-hydroxy-cholane. Yield $92 \% ;{ }^{1} \mathrm{H}$ NMR $\left(300 \mathrm{MHz}, \mathrm{CDCl}_{3}\right) \delta: 8.13(\mathrm{~s}, 1 \mathrm{H}), 8.02$ $(\mathrm{s}, 1 \mathrm{H}), 5.25(\mathrm{~s}, 1 \mathrm{H}), 4.87-4.79(\mathrm{~m}, 1 \mathrm{H}), 3.60(\mathrm{t}, J=6.3 \mathrm{~Hz}$, 2H), 1.9-1.0 (m), $0.92(\mathrm{~s}, 3 \mathrm{H}), 0.83(\mathrm{~d}, J=5.7 \mathrm{~Hz}, 3 \mathrm{H}), 0.74$ $(\mathrm{s}, 3 \mathrm{H}) ;{ }^{13} \mathrm{C}$ NMR $\left(100 \mathrm{MHz}, \mathrm{CDCl}_{3}\right) \delta: 160.60,160.48$, 75.94, 73.96, 62.79, 49.18, 47.51, 44.90, 41.67, 35.54, 34.96, $34.61,34.13,33.91,32.05,31.66,29.12,27.34,26.74,26.37$, $25.851,25.64,23.38,22.81,17.73,12.22$.

2.1.2.3. $3 \alpha, 7 \alpha$-diformyloxy-5 $\beta$-24-hydroxy-cholane. Yield $66 \% ;{ }^{1} \mathrm{H}$ NMR $\left(300 \mathrm{MHz}, \mathrm{CDCl}_{3}\right) \delta: 8.08(\mathrm{~s}, 1 \mathrm{H}), 8.03(\mathrm{~s}$, $1 \mathrm{H}), 5.03(\mathrm{~s}, 1 \mathrm{H}), 4.76-4.69(\mathrm{~m}, 1 \mathrm{H}), 3.63-3.59(\mathrm{~m}, 2 \mathrm{H})$, 2.1-1.0 (m), $0.96(\mathrm{~s}, 3 \mathrm{H}), 0.96-0.92$ (unresolved d, 3H), 0.65 $(\mathrm{s}, 3 \mathrm{H}) ;{ }^{13} \mathrm{CNMR}\left(75 \mathrm{MHz}, \mathrm{CDCl}_{3}\right) \delta: 160.73,160.70,73.98$, 71.35, 63.39, 55.82, 55.02, 42.56, 40.88, 39.34, 37.79, 35.44, $34.69,34.48,33.89,31.69,31.39,29.20,28.00,26.64,23.42$, $22.57,20.53,1.55,11.64$. 
2.1.2.4. $3 \alpha, 7 \beta$-diformyloxy-5 $\beta$-24-hydroxy-cholane. Yield $82 \% ;{ }^{1} \mathrm{H}$ NMR $\left(300 \mathrm{MHz}, \mathrm{CDCl}_{3}\right) \delta: 8.03(\mathrm{~s} 1 \mathrm{H}), 7.99(\mathrm{~s}$, $1 \mathrm{H}), 4.94-4.79$ (m, 2H), 3.60 (t, $J=6.6 \mathrm{~Hz}, 2 \mathrm{H}), 1.88-1.04$ (m), 0.99 (s, 3H), $0.93(\mathrm{~d}, J=6.3 \mathrm{~Hz}, 3 \mathrm{H}), 0.69(\mathrm{~s}, 3 \mathrm{H})$; ${ }^{13} \mathrm{C}$ NMR (75 MHz, $\mathrm{CDCl}_{3}$ ) $\delta: 161.01,160.61,73.60,73.35$, 63.33, 55.25, 55.06, 43.48, 41.94, 39.78, 39.73, 39.34, 35.35, $34.27,33.85,32.78,32.65,31.73,29.22,28.36,26.27,25.76$, $23.11,21.13,18.63,11.96$.

\subsubsection{3 $\alpha$-Formyloxy-5 $\beta$-24-hydroxy-cholane. Yield} $70 \% ;{ }^{1} \mathrm{H}$ NMR $\left(300 \mathrm{MHz}, \mathrm{CDCl}_{3}\right) \delta: 8.04(\mathrm{~s}, 1 \mathrm{H}), 4.89-4.80$ $(\mathrm{m}, 1 \mathrm{H}), 3.61(\mathrm{t}, J=5.1 \mathrm{~Hz}, 2 \mathrm{H}), 2.0-0.98(\mathrm{~m}), 0.94(\mathrm{~s}, 3 \mathrm{H})$, $0.93(\mathrm{~d}, J=6.6 \mathrm{~Hz}, 3 \mathrm{H}), 0.65(\mathrm{~s}, 3 \mathrm{H}) ;{ }^{13} \mathrm{C}$ NMR $(75 \mathrm{MHz}$, $\left.\mathrm{CDCl}_{3}\right) \delta: 160.82,74.42,63.58,56.47,56.16,42.69,41.90$, $40.44,40.12,35.76,35.55,34.94,34.56,32.19,31.82$, $29.38,28.28,26.98,26.62,26.31,24.18,23.31,20.83$, $18.62,12.03$.

\subsubsection{General procedure for the preparation of formyl-23-iodo-24-nor-cholanes}

In a $100 \mathrm{~mL}$ two-necked rb flask fitted with a reflux condenser and a pressure equalizing dropping funnel, formylated bile acid $(5.36 \mathrm{mmol})$ and lead tetraacetate $(5.0 \mathrm{~g}$, $11.4 \mathrm{mmol})$ were suspended in $\mathrm{CCl}_{4}(15 \mathrm{~mL})$. The mixture was refluxed and irradiated with two $100 \mathrm{~W}$ tungsten lamps. After $5 \mathrm{~min}, \mathrm{I}_{2}(2.7 \mathrm{~g}, 10.6 \mathrm{mmol})$ in $\mathrm{CCl}_{4}(60 \mathrm{~mL})$ was added through the dropping funnel until violet color persisted. Heating and irradiation was continued for an additional $1 \mathrm{~h}$. The reaction mixture was filtered through celite, washed with $10 \%$ sodium thiosulphate solution $(50 \mathrm{~mL})$, water $(20 \mathrm{~mL})$ and brine $(25 \mathrm{~mL})$, dried over anhyd. $\mathrm{Na}_{2} \mathrm{SO}_{4}$ and concentrated. The crude-product was purified by column chromatography on silica gel $(2.8 \mathrm{~cm} \times 19.5 \mathrm{~cm})$ using EtOAc/ $\mathrm{CHCl}_{3}(2-5: 98-95$, v/v) to yield 23-iodo derivatives.

2.1.3.1. $3 \alpha, \quad 7 \alpha, \quad 12 \alpha$-triformyloxy-5 $\beta$-23-iodo-24-norcholane. Yield $60 \% ;{ }^{1} \mathrm{H}$ NMR $\left(300 \mathrm{MHz}, \mathrm{CDCl}_{3}\right) \delta: 8.16(\mathrm{~s}$, $1 \mathrm{H}), 8.10(\mathrm{~s}, 1 \mathrm{H}), 8.02(\mathrm{~s}, 1 \mathrm{H}), 5.28(\mathrm{bs}, 1 \mathrm{H}), 5.07$ (bs, $1 \mathrm{H})$, $4.76-4.68(\mathrm{~m}, 1 \mathrm{H}), 3.33-3.26(\mathrm{~m}, 1 \mathrm{H}), 3.07(\mathrm{dd}, J=8.4 \mathrm{~Hz}$, $J=7.8 \mathrm{~Hz}, 1 \mathrm{H}), 2.20-1.24(\mathrm{~m}, 23 \mathrm{H}), 1.194-1.090(\mathrm{~m}, 2 \mathrm{H})$, $0.952(\mathrm{~s}, 3 \mathrm{H}), 0.844(\mathrm{~d}, J=6.0 \mathrm{~Hz}, 3 \mathrm{H}), 0.782(\mathrm{~s}, 3 \mathrm{H}) ;{ }^{13} \mathrm{C}$ NMR $\left(75 \mathrm{MHz}, \mathrm{CDCl}_{3}\right) \delta: 160.49,160.47,160.39,75.13$, $73.63,70.57,47.02,45.05,42.88,40.72,39.74,37.64$, $36.42,34.45,34.38,34.22,31.27,28.49,27.13,26.52$, 25.49, 22.29, 16.94, 12.10, 4.69 .

2.1.3.2. $3 \alpha, \quad 12 \alpha$-diformyloxy-5 $\beta$-23-iodo-24-nor-cholane. Yield $79 \%$; ${ }^{1} \mathrm{H}$ NMR $\left(300 \mathrm{MHz}, \mathrm{CDCl}_{3}\right) \delta: 8.12(\mathrm{~s}, 1 \mathrm{H})$, $8.03(\mathrm{~s}, 1 \mathrm{H}), 5.25(\mathrm{~s}, 1 \mathrm{H}), 4.83(\mathrm{~m}, 1 \mathrm{H}), 3.30(\mathrm{~m}, 1 \mathrm{H}), 3.05$ (m, 2H), 2.05-0.95 (m), $0.92(\mathrm{~s}, 3 \mathrm{H}), 0.83(\mathrm{~d}, J=6.3 \mathrm{~Hz}, 3 \mathrm{H})$, $0.76(\mathrm{~s}, 3 \mathrm{H}) ;{ }^{13} \mathrm{C}$ NMR $\left(75 \mathrm{MHz}, \mathrm{CDCl}_{3}\right) \delta: 160.61,160.47$, 75.91, 74.04, 49.23, 47.20, 45.06, 41.68, 39.91, 36.55, 35.56, $34.63,33.99,32.06,27.36,26.73,26.44,25.86,25.70,23.37$, $22.91,16.97,12.31,4.85$.
2.1.3.3. $3 \alpha, 7 \alpha$-diformyloxy-5 $\beta$-23-iodo-24-nor-cholane: Yield 99\%; ${ }^{1} \mathrm{H}$ NMR $\left(300 \mathrm{MHz}, \mathrm{CDCl}_{3}\right) \delta: 8.07(\mathrm{~s}, 1 \mathrm{H})$, $8.02(\mathrm{~s}, 1 \mathrm{H}), 5.03(\mathrm{~s}, 1 \mathrm{H}), 4.76-4.68(\mathrm{~m}, 1 \mathrm{H}), 3.32-3.27$ (m, 1H), 3.12-3.06 (m, 1H), 2.18-1.01 (m), $0.95(\mathrm{~s}, 3 \mathrm{H})$, $0.93(\mathrm{~d}, J=6.0 \mathrm{~Hz}, 3 \mathrm{H}), 0.67(\mathrm{~s}, 3 \mathrm{H}) ;{ }^{13} \mathrm{C}$ NMR $(100 \mathrm{MHz}$, $\left.\mathrm{CDCl}_{3}\right) \delta:$ 160.66, 74.05, 71.38, 55.68, 50.15, 42.84, 41.03, $40.25,39.46,37.95,37.09,34.83,34.63,34.05,31.51$, $27.98,26.79,23.49,22.67,20.66,17.87,11.76,4.83$.

2.1.3.4. $3 \alpha, \quad 7 \beta$-diformyloxy-5 $\beta$-23-iodo-24-nor-cholane. Yield 91\%; ${ }^{1} \mathrm{H}$ NMR $\left(400 \mathrm{MHz}, \mathrm{CDCl}_{3}\right) \delta: 8.02(\mathrm{~s}, 1 \mathrm{H}), 7.98$ (s, $1 \mathrm{H}), 4.93-4.86(\mathrm{~m}, 1 \mathrm{H}), 4.85-4.77(\mathrm{~m}, 1 \mathrm{H}), 3.33-3.27$ (m, 1H), 3.12-3.06 (m, 1H), 2.03-1.98 (m, 2H), 1.87-1.07 (m), $0.99(\mathrm{~s}, 3 \mathrm{H}), 0.92(\mathrm{~d}, J=6.4 \mathrm{~Hz}, 3 \mathrm{H}), 0.70(\mathrm{~s}, 3 \mathrm{H}) ;{ }^{13} \mathrm{C}$ NMR $\left(100 \mathrm{MHz}, \mathrm{CDCl}_{3}\right) \delta: 160.92,160.53,73.62,73.42$, $55.38,54.96,43.78,42.12,40.25,39.92,39.52,36.97$, $34.44,34.01,32.93,32.85,28.31,26.43,25.82,23.22$, 21.25, 17.97, 12.01, 5.1.

2.1.3.5. 3 $\alpha$-Formyloxy-5 $\beta$-23-iodo-24-nor-cholane. Yield $76 \% ;{ }^{1} \mathrm{H}$ NMR $\left(300 \mathrm{MHz}, \mathrm{CDCl}_{3}\right) \delta: 8.02(\mathrm{~s}, 1 \mathrm{H}), 4.87-4.80$ (m, 1H), 3.32-3.25 (m, 1H), 3.12-3.04 (m, 1H), 2.06-1.05 (m), $0.92(\mathrm{~s}, 3 \mathrm{H}), 0.90(\mathrm{~d}, J=6.0 \mathrm{~Hz}, 3 \mathrm{H}), 0.65(\mathrm{~s}, 1 \mathrm{H})$; ${ }^{13} \mathrm{C}$ NMR $\left(75 \mathrm{MHz}, \mathrm{CDCl}_{3}\right) \delta: 160.73,74.33,56.41,55.82$, $42.79,41.84,40.39,40.28,40.07,37.15,35.72,34.91$, $34.54,32.17,28.15,26.93,26.60,26.26,24.11,23.30$, $20.79,17.81,12.03,5.16$.

\subsubsection{General procedure for the synthesis of formyl 24-iodo cholanes}

To a solution of $\mathrm{PPh}_{3}(0.59 \mathrm{~g}, 2.3 \mathrm{mmol})$ and imidazole $(0.16 \mathrm{~g}, 2.3 \mathrm{mmol})$ in dichloromethane $(10 \mathrm{~mL})$ at $0{ }^{\circ} \mathrm{C}$, iodine $(0.58 \mathrm{~g}, 2.3 \mathrm{mmol})$ was added in portions over $20 \mathrm{~min}$. The formylated cholanol $(0.72 \mathrm{~g}, 1.5 \mathrm{mmol})$ in dichloromethane $(5 \mathrm{~mL})$ was added and warmed to $\mathrm{rt}$. After $36 \mathrm{~h}$, the reaction mixture was diluted with $\mathrm{CHCl}_{3}$ $(30 \mathrm{~mL})$, washed with $10 \%$ aq. sodium thiosulphate solution $(30 \mathrm{~mL})$, and water $(20 \mathrm{~mL})$ dried over anhyd. $\mathrm{Na}_{2} \mathrm{SO}_{4}$. The crude-product was purified on silica gel column using EtOAc/ $\mathrm{CHCl}_{3}(2-5: 98-95, \mathrm{v} / \mathrm{v})$.

2.1.4.1. $3 \alpha, 7 \alpha, \quad 12 \alpha$-triformyloxy-5 $\beta$-24-iodo-cholane. Yield 95\%; ${ }^{1} \mathrm{H}$ NMR $\left(400 \mathrm{MHz}, \mathrm{CDCl}_{3}\right) \delta: 8.16(\mathrm{~s}, 1 \mathrm{H})$, $8.10(\mathrm{~s}, 1 \mathrm{H}), 8.02(\mathrm{~s}, 1 \mathrm{H}), 5.26(\mathrm{~s}, 1 \mathrm{H}), 5.08(\mathrm{~s}, 1 \mathrm{H})$, 4.75-4.68 (m, 1H), 3.21-3.08 (m, 2H), 2.18-1.05 (m), 0.95 $(\mathrm{s}, 3 \mathrm{H}), 0.85(\mathrm{~d}, J=6.4 \mathrm{~Hz}, 3 \mathrm{H}), 0.76(\mathrm{~s}, 3 \mathrm{H}) ;{ }^{13} \mathrm{C} \mathrm{NMR}$ $\left(100 \mathrm{MHz}, \mathrm{CDCl}_{3}\right) \delta: 160.49,75.35,73.76,70.21,47.36$, $45.08,43.02,40.90,37.84,36.59,34.53,34.34,31.41,30.20$, $28.63,27.29,26.64,25.60,22.82,22.35,17.97,12.16,7.32$.

2.1.4.2. $3 \alpha, \quad 12 \alpha$-diformyloxy-5 $\beta$-24-iodo-cholane. Yield $73 \% ;{ }^{1} \mathrm{H}$ NMR $\left(300 \mathrm{MHz}, \mathrm{CDCl}_{3}\right) \delta: 8.14(\mathrm{~s}, 1 \mathrm{H}), 8.03(\mathrm{~s}$, $1 \mathrm{H}), 5.25(\mathrm{~s}, 1 \mathrm{H}), 4.87-4.80(\mathrm{~m}, 1 \mathrm{H}), 3.23-3.08(\mathrm{~m}, 2 \mathrm{H})$, $1.90-1.03(\mathrm{~m}), 0.93(\mathrm{~s}, 3 \mathrm{H}), 0.84(\mathrm{~d}, J=6.3 \mathrm{~Hz}, 3 \mathrm{H}), 0.75$ (s, $3 \mathrm{H}) ;{ }^{13} \mathrm{C}$ NMR $\left(100 \mathrm{MHz}, \mathrm{CDCl}_{3}\right) \delta: 160.57,160.48,76.04$, 74.10, 49.31, 47.54, 45.08, 42.09, 36.64, 35.69, 34.74, 
$34.59,34.29,34.08,32.19,30.29,27.50,26.85,26.54$, $25.96,25.80,23.50,22.96,12.38,7.50$.

2.1.4.3. $3 \alpha, \quad 7 \alpha$-diformyloxy-5 $\beta$-24-iodo-cholane. Yield $87 \% ;{ }^{1} \mathrm{H}$ NMR $\left(300 \mathrm{MHz}, \mathrm{CDCl}_{3}\right) \delta: 8.08(\mathrm{~s}, 1 \mathrm{H}), 8.03(\mathrm{~s}$, $1 \mathrm{H}), 5.03(\mathrm{~s}, 1 \mathrm{H}), 4.77-4.69(\mathrm{~m}, 1 \mathrm{H}), 3.23-3.08(\mathrm{~m}, 2 \mathrm{H})$, 2.1-1.0 (m), $0.95(\mathrm{~s}, 3 \mathrm{H}), 0.93(\mathrm{~d}, J=6.6 \mathrm{~Hz}), 0.66(\mathrm{~s}, 3 \mathrm{H})$; ${ }^{13} \mathrm{C} \mathrm{NMR}\left(75 \mathrm{MHz}, \mathrm{CDCl}_{3}\right) \delta: 160.70,73.99,71.32,55.70$, $50.06,42.62,40.91,39.35,37.82,36.75,34.97,34.72$, $34.51,33.92,31.42,30.22,28.05,26.68,23.46,22.62$, $20.54,18.67,11.68,7.78$.

2.1.4.4. $3 \alpha, \quad 7 \beta$-diformyloxy-5 $\beta$-24-iodo-cholane. Yield $86 \% ;{ }^{1} \mathrm{H}$ NMR $\left(300 \mathrm{MHz}, \mathrm{CDCl}_{3}\right) \delta: 8.03(\mathrm{~s}, 1 \mathrm{H}), 7.98(\mathrm{~s}$, $1 \mathrm{H}), 4.94-4.79(\mathrm{~m}, 2 \mathrm{H}), 3.23-3.08(\mathrm{~m}, 2 \mathrm{H}), 2.0-1.0(\mathrm{~m})$, 0.99 (s, 3H), $0.92(\mathrm{~d}, J=6.6 \mathrm{~Hz}), 0.69(\mathrm{~s}, 3 \mathrm{H}) ;{ }^{13} \mathrm{C} \mathrm{NMR}$ $\left(75 \mathrm{MHz}, \mathrm{CDCl}_{3}\right) \delta: 160.86,160.48,73.45,73.23,55.17$, $54.84,43.46,41.88,39.68,39.28,36.65,34.79,34.23$, $33.80,32.73,32.62,30.18,28.34,26.24,25.71,23.09$, $21.09,18.67,11.94,7.70$.

2.1.4.5. $3 \alpha$-Formyloxy-5 $\beta$-24-iodo-cholane. Yield $94 \% ;{ }^{1} \mathrm{H}$ NMR $\left(300 \mathrm{MHz}, \mathrm{CDCl}_{3}\right) \delta: 8.04(\mathrm{~s}, 1 \mathrm{H}), 4.9-4.8(\mathrm{~m}, 1 \mathrm{H})$, 3.24-3.1 (m, 2H), 2.0-1.0 (m), $0.94(\mathrm{~s}, 3 \mathrm{H}), 0.92(\mathrm{~d}$, $J=6.6 \mathrm{~Hz}, 3 \mathrm{H}), 0.65(\mathrm{~s}, 3 \mathrm{H}) ;{ }^{13} \mathrm{C}$ NMR $\left(75 \mathrm{MHz}, \mathrm{CDCl}_{3}\right)$ $\delta: 160.80,74.40,56.46,56.03,42.71,41.90,40.44,40.09$, $36.83,35.76,35.07,34.94,34.56,32.19,30.35,28.28,26.96$, 26.62, 26.31, 24.18, 23.31, 20.83,18.71, 12.03, 7.91.

\subsubsection{General procedure for the synthesis of diethyl 23- and 24-phosphonocholanates}

In a $50 \mathrm{~mL}$ rb flask fitted with a reflux condenser, formylated iodocholane $(1.9 \mathrm{mmol})$ in $\mathrm{P}(\mathrm{OEt})_{3}(1.6 \mathrm{~mL}, 9.5 \mathrm{mmol})$ was heated at $160^{\circ} \mathrm{C}$ under nitrogen. After $6 \mathrm{~h}$, excess $\mathrm{P}(\mathrm{OEt})_{3}$ and other volatiles were removed under vacuum. The product was purified by column chromatography on silica gel using EtOAc/ $\mathrm{CHCl}_{3}(30: 70$, v/v), yielding phosphonocholanate a viscous liquid.

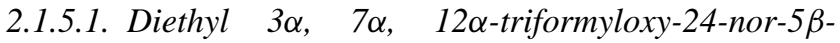
cholane-23-phosphonate. Yield 71\%; ${ }^{1} \mathrm{H}$ NMR $(300 \mathrm{MHz}$, $\left.\mathrm{CDCl}_{3}\right) \delta: 8.12(\mathrm{~s}, 1 \mathrm{H}), 8.06(\mathrm{~s}, 1 \mathrm{H}), 7.98(\mathrm{~s}, 1 \mathrm{H}), 5.22$ (s, 1H), $5.03(\mathrm{~s}, 1 \mathrm{H}), 4.71-4.63(\mathrm{~m}, 1 \mathrm{H}), 4.08-4.00(\mathrm{~m}$, $4 \mathrm{H}), 2.15-1.39(\mathrm{~m}), 1.33-1.24(\mathrm{~m}, 6 \mathrm{H}), 1.21-1.0(\mathrm{~m}), 0.90$ $(\mathrm{s}, 3 \mathrm{H}), 0.80(\mathrm{~d}, J=6.3 \mathrm{~Hz}, 3 \mathrm{H}), 0.71(\mathrm{~s}, 3 \mathrm{H}) ;{ }^{13} \mathrm{C} \mathrm{NMR}$ $\left(75 \mathrm{MHz}, \mathrm{CDCl}_{3}\right) \delta: 160.46,160.38,75.06,73.58,61.45$ $(\mathrm{d}, J=6 \mathrm{~Hz}), 46.63,44.84,42.81,40.65,37.57,35.27(\mathrm{~d}$, $J=17 \mathrm{~Hz}$ ), 34.38, 34.30, 34.14, 31.19, 28.40, 27.73, 26.92, $26.43,25.40,22.61,22.19,21.80(\mathrm{~d}, J=140 \mathrm{~Hz}), 17.11$, $16.33(\mathrm{~d}, J=5 \mathrm{~Hz}), 12.02 ;{ }^{31} \mathrm{P}$ NMR $\left(162 \mathrm{MHz}, \mathrm{CDCl}_{3}\right) \delta$ : 32.74; MALDI-TOF MS: calc. for $M+\mathrm{Na}^{+}, M+\mathrm{K}^{+}$: 607.6, 623.8; obsd. 607.7, 623.8.

2.1.5.2. Diethyl $3 \alpha, 12 \alpha$-diformyloxy-24-nor-5 $\beta$-cholane23-phosphonate. Yield $80 \% ;{ }^{1} \mathrm{H} \mathrm{NMR}\left(300 \mathrm{MHz}, \mathrm{CDCl}_{3}\right) \delta$ : $8.13(\mathrm{~s}, 1 \mathrm{H}), 8.04(\mathrm{~s}, 1 \mathrm{H}), 5.24(\mathrm{bs}, 1 \mathrm{H}), 4.87-4.80(\mathrm{~m}, 1 \mathrm{H})$, $3.735(\mathrm{~d}, J=9.0 \mathrm{~Hz}, 6 \mathrm{H}), 1.9-1.0(\mathrm{~m}, 26 \mathrm{H}), 0.93(\mathrm{~s}, 3 \mathrm{H}), 0.84$ $(\mathrm{d}, J=6.6 \mathrm{~Hz}, 3 \mathrm{H}), 0.75(\mathrm{~s}, 3 \mathrm{H}) ;{ }^{13} \mathrm{C} \mathrm{NMR}\left(75 \mathrm{MHz}, \mathrm{CDCl}_{3}\right)$ $\delta: 160.45,160.33,75.69,73.81,61.27(\mathrm{~d}, J=7 \mathrm{~Hz}), 49.03$, $46.76,44.79,44.54,35.41,35.32(\mathrm{~d}, J=14 \mathrm{~Hz}), 34.49,34.00$, $33.83,31.90,27.78,27.72,27.17,26.60,26.28,25.72,25.54$, $23.24,22.15,21.70(\mathrm{~d}, J=135 \mathrm{~Hz}), 17.05,16.30(\mathrm{~d}, J=6 \mathrm{~Hz})$, $12.19 ;{ }^{31} \mathrm{P}$ NMR $\left(162 \mathrm{MHz}, \mathrm{CDCl}_{3}\right) \delta: 32.81$; MALDI-TOF MS: calc. for $M+\mathrm{Na}^{+}, M+\mathrm{K}^{+}: 564.0,579.9$; obsd. 563.7, 579.8 .

2.1.5.3. Diethyl $3 \alpha, 7 \alpha$-diformyloxy-24-nor-5 $\beta$-cholane-23phosphonate. Yield $75 \% ;{ }^{1} \mathrm{H}$ NMR $\left(300 \mathrm{MHz}, \mathrm{CDCl}_{3}\right) \delta$ : $8.09(\mathrm{~s}, 1 \mathrm{H}), 8.03(\mathrm{~s}, 1 \mathrm{H}), 5.03(\mathrm{~s}, 1 \mathrm{H}), 4.72(\mathrm{~m}, 1 \mathrm{H})$, 4.14-4.02 (m, 4H), 2.18-1.00 (m), $0.95(\mathrm{bs}, 6 \mathrm{H}), 0.68(\mathrm{~s}, 3 \mathrm{H})$; ${ }^{13} \mathrm{C}$ NMR $\left(100 \mathrm{MHz}, \mathrm{CDCl}_{3}\right) \delta: 160.56,73.87,71.18,61.39$ $(\mathrm{d}, J=5.0 \mathrm{~Hz}), 55.18,50.00,42.59,40.91,39.31,37.83,35.83$ (d, $J=15.9 \mathrm{~Hz}), 34.70,34.51,33.90,31.40,27.96,27.78$, 26.67, 23.37, 22.55, 21.89 (d, $J=133.5 \mathrm{~Hz}), 20.53,17.98$, $16.38(\mathrm{~d}, J=4.3 \mathrm{~Hz}), 11.66 ;{ }^{31} \mathrm{P} \mathrm{NMR}\left(162 \mathrm{MHz}, \mathrm{CDCl}_{3}\right) \delta$ : 32.84 .

2.1.5.4. Diethyl $3 \alpha, 7 \beta$-diformyloxy-24-nor-5 $\beta$-cholane-23phosphonate. Yield $88 \% ;{ }^{1} \mathrm{H}$ NMR $\left(300 \mathrm{MHz}, \mathrm{CDCl}_{3}\right) \delta$ : $8.02(\mathrm{~s}, 1 \mathrm{H}), 7.97(\mathrm{~s}, 1 \mathrm{H}), 4.94-4.80(\mathrm{~m}, 2 \mathrm{H}), 4.12-4.05$ (m, 4H), 1.87-1.02 (m), $0.98(\mathrm{~s}, 3 \mathrm{H}), 0.91(\mathrm{~d}, J=6.0 \mathrm{~Hz}$, $3 \mathrm{H}), 0.68(\mathrm{~s}, 3 \mathrm{H}) ;{ }^{13} \mathrm{C} \mathrm{NMR}\left(100 \mathrm{MHz}, \mathrm{CDCl}_{3}\right) \delta: 160.88$, $160.51,73.53,73.33,61.49(\mathrm{~d}, J=5.3 \mathrm{~Hz}), 55.27,54.50$, 43.56, 42.02, 39.82, 39.40, $35.83(\mathrm{~d}, J=16.1 \mathrm{~Hz}), 34.35$, $33.91,32.85,32.75,28.18,28.02,26.35,25.76,23.13,22.03$ $(\mathrm{d}, J=139.7 \mathrm{~Hz}), 21.18,18.09,16.39$ (d, $J=4.2 \mathrm{~Hz}), 12.04$; ${ }^{31} \mathrm{P}$ NMR $\left(162 \mathrm{MHz}, \mathrm{CDCl}_{3}\right) \delta$ : 32.92; LRMS-ESI: calc. for $M+\mathrm{Na}^{+}:$563.3; obsd. 563.7.

2.1.5.5. Diethyl 3 $\alpha$-formyloxy-24-nor-5 $\beta$-cholane-23phosphonate. Yield $75 \%$; ${ }^{1} \mathrm{H}$ NMR $\left(300 \mathrm{MHz}, \mathrm{CDCl}_{3}\right)$ $\delta: 8.00(\mathrm{~s}, 1 \mathrm{H}), 4.81-4.78(\mathrm{~m}, 1 \mathrm{H}), 4.11-3.96(\mathrm{~m}, 4 \mathrm{H})$, 1.94-1.04 (m), $0.90(\mathrm{~s}, 3 \mathrm{H}), 0.88(\mathrm{~d}, J=9.0 \mathrm{~Hz}, 3 \mathrm{H}), 0.61(\mathrm{~s}$, $3 \mathrm{H}) ;{ }^{13} \mathrm{C}$ NMR $\left(75 \mathrm{MHz}, \mathrm{CDCl}_{3}\right) \delta: 160.89,74.49,61.58(\mathrm{~d}$, $J=7 \mathrm{~Hz}$ ), 56.53, 55.61, 42.81, 41.00, 40.53, 40.18, 36.15 (d, $J=17 \mathrm{~Hz}), 35.88,35.15,34.67,32.30,28.17,28.13,27.07$, 26.72, 26.39, 24.25, 23.41, 22.17 (d, $J=139 \mathrm{~Hz}), 20.92$, $18.13,16.57(\mathrm{~d}, J=6.2 \mathrm{~Hz}), 12.17 ;{ }^{31} \mathrm{P}$ NMR $(162 \mathrm{MHz}$, $\left.\mathrm{CDCl}_{3}\right) \delta$ : 33.35; MALDI-TOF MS: calc. for $M+\mathrm{Na}^{+}$: 519.3; obsd. 519.7 .

2.1.5.6. Diethyl $3 \alpha, 7 \alpha, 12 \alpha$-triformyloxy-5 $\beta$-cholane-24phosphonate. Yield $97 \% ;{ }^{1} \mathrm{H}$ NMR $\left(300 \mathrm{MHz}, \mathrm{CDCl}_{3}\right) \delta$ : $8.01(\mathrm{~s}, 1 \mathrm{H}), 7.96(\mathrm{~s}, 1 \mathrm{H}), 7.87(\mathrm{~s}, 1 \mathrm{H}), 5.11(\mathrm{~s}, 1 \mathrm{H}), 4.92$ (s, 1H), $4.56(\mathrm{~m}, 1 \mathrm{H}), 3.95-3.91(\mathrm{~m}, 4 \mathrm{H}), 2.04-0.91(\mathrm{~m})$, $0.80(\mathrm{~s}, 3 \mathrm{H}), 0.70(\mathrm{~d}, J=6.4 \mathrm{~Hz}, 3 \mathrm{H}), 0.61(\mathrm{~s}, 3 \mathrm{H}) ;{ }^{13} \mathrm{C}$ NMR $\left(100 \mathrm{MHz}, \mathrm{CDCl}_{3}\right) \delta: 160.44,75.24,73.64,70.58$, $61.27(\mathrm{~d}, J=5.8 \mathrm{~Hz}), 47.22,44.94,42.88,40.76,37.69,36.59$ $(\mathrm{d}, J=15.9 \mathrm{~Hz}), 34.82,34.47,34.41,34.21,31.29,28.48$, 27.17, 26.52, 25.91 (d, $J=139.7 \mathrm{~Hz}), 25.47,22.69,22.24$, $18.99,18.94,17.63,16.37(\mathrm{~d}, J=4.9 \mathrm{~Hz}), 12.03 ;{ }^{31} \mathrm{P}$ NMR 
$\left(162 \mathrm{MHz}, \mathrm{CDCl}_{3}\right) \delta: 31.69$; LRMS-ESI: calc. for $M+\mathrm{Na}^{+}$, $M+\mathrm{K}^{+}:$621.3, 637.3; obsd. 621, 637.

2.1.5.7. Diethyl $3 \alpha, 12 \alpha$-diformyloxy-5 $\beta$-cholane-24-phosphonate. Yield $83 \% ;{ }^{1} \mathrm{H}$ NMR $\left(400 \mathrm{MHz}, \mathrm{CDCl}_{3}\right) \delta$ : $8.13(\mathrm{~s}, 1 \mathrm{H}), 8.03(\mathrm{~s}, 1 \mathrm{H}), 5.24(\mathrm{~s}, 1 \mathrm{H}), 4.87-4.81(\mathrm{~m}$, $1 \mathrm{H})$, 4.14-4.04 (m, 4H), 1.91-1.4 (m), 1.34-1.30 (m, $6 \mathrm{H}), \quad 1.0-0.90(\mathrm{~m}), 0.92(\mathrm{~s}, 3 \mathrm{H}), 0.84(\mathrm{~d}, J=6.4 \mathrm{~Hz})$, $0.74(\mathrm{~s}, 3 \mathrm{H}) ;{ }^{13} \mathrm{C}$ NMR $\left(100 \mathrm{MHz}, \mathrm{CDCl}_{3}\right) \delta: 160.55$, $160.47,76.01,74.04,61.34(\mathrm{~d}, J=5.9 \mathrm{~Hz}), 49.21,47.45$, 44.97, 41.73, 36.73 (d, $J=16.9 \mathrm{~Hz}), 35.60,34.65,34.18$, $33.98,32.09,27.39,26.75,26.44,26.00(\mathrm{~d}, J=140.9 \mathrm{~Hz})$, 25.86, 25.70, 23.38, 22.86, 19.08 (d, $J=3.3 \mathrm{~Hz}), 17.67$, $16.40(\mathrm{~d}, J=5.0 \mathrm{~Hz}), 12.26 ;{ }^{31} \mathrm{P}$ NMR $\left(162 \mathrm{MHz}, \mathrm{CDCl}_{3}\right)$ $\delta$ : 30.57; LRMS-ESI: calc. for $M+\mathrm{Na}^{+}$: 577.3 ; obsd. 578.

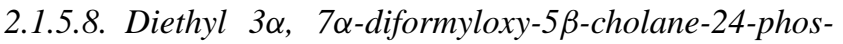
phonate. Yield $98 \% ;{ }^{1} \mathrm{H}$ NMR $\left(400 \mathrm{MHz}, \mathrm{CDCl}_{3}\right) \delta: 8.08$ $(\mathrm{s}, 1 \mathrm{H}), 8.03(\mathrm{~s}, 1 \mathrm{H}), 5.03(\mathrm{~s}, 1 \mathrm{H}), 4.77-4.69(\mathrm{~m}, 1 \mathrm{H})$, $4.12-4.06(\mathrm{~m}, 4 \mathrm{H}), 2.1-1.38(\mathrm{~m}), 1.33(\mathrm{t}, J=7.2 \mathrm{~Hz}, 6 \mathrm{H})$, $1.25-1.0(\mathrm{~m}), 0.95(\mathrm{~s}, 3 \mathrm{H}), 0.93(\mathrm{~d}, J=6.0 \mathrm{~Hz}, 3 \mathrm{H})$, 0.65 (s, 3H); ${ }^{13} \mathrm{C}$ NMR $\left(100 \mathrm{MHz}, \mathrm{CDCl}_{3}\right) \delta: 160.59$, $74.02,71.37,61.34(\mathrm{~d}, J=5.9 \mathrm{~Hz}), 55.84,50.11,42.68$, $41.02,39.43,37.95,36.94(\mathrm{~d}, J=16.1 \mathrm{~Hz}), 35.39,34.79$, $34.62,34.01,31.50,28.02,26.75,26.12$ (d, $J=138.4 \mathrm{~Hz})$, 26.75, 23.46, 22.61, 20.61, 19.07 (d, $J=4.0 \mathrm{~Hz}), 18.50$, $16.43(\mathrm{~d}, J=5.0 \mathrm{~Hz}), 11.66 ;{ }^{31} \mathrm{P} \mathrm{NMR}\left(162 \mathrm{MHz}, \mathrm{CDCl}_{3}\right)$ $\delta$ : 31.93; LRMS-ESI: calc. for $M+\mathrm{Na}^{+}$: 577.3; obsd. 578.

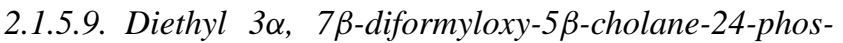
phonate. Yield $93 \% ;{ }^{1} \mathrm{H}$ NMR $\left(300 \mathrm{MHz}, \mathrm{CDCl}_{3}\right) \delta: 8.03$ (s, 1H), 7.99 (s, 1H), 4.94-4.79 (m, 2H), 4.12-4.06 (m, 4H), 2.1-1.37 (m), $1.33(\mathrm{t}, J=7.2 \mathrm{~Hz}, 6 \mathrm{H}), 1.25-1.0(\mathrm{~m}), 0.99$ $(\mathrm{s}, 3 \mathrm{H}), 0.93(\mathrm{~d}, J=6.6 \mathrm{~Hz}, 3 \mathrm{H}), 0.68(\mathrm{~s}, 3 \mathrm{H}) ;{ }^{13} \mathrm{C}$ NMR $\left(100 \mathrm{MHz}, \mathrm{CDCl}_{3}\right) \delta: 160.67,160.27,73.34,73.10,61.12(\mathrm{~d}$, $J=5.9 \mathrm{~Hz}), 55.10,54.81,43.34,41.82,39.62,39.21,36.69$ (d, $J=17.0 \mathrm{~Hz}), 35.06,34.14,33.70,32.66,32.53,28.17$, 26.14, 25.80 (d, $J=138.7 \mathrm{~Hz}), 25.57,22.93,20.97,18.86$ $(\mathrm{d}, J=3.5 \mathrm{~Hz}), 18.34,16.21(\mathrm{~d}, J=5.2 \mathrm{~Hz}), 11.77 ;{ }^{31} \mathrm{P}$ NMR $\left(162 \mathrm{MHz}, \mathrm{CDCl}_{3}\right) \delta: 31.87$; LRMS-ESI: calc. for $M+\mathrm{Na}^{+}$: 577.3; obsd. 577.7.

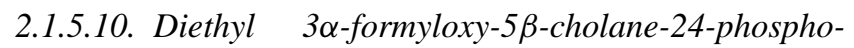
nate. Yield 95\%; ${ }^{1} \mathrm{H}$ NMR $\left(400 \mathrm{MHz}, \mathrm{CDCl}_{3}\right)$ s: 8.04 $(\mathrm{s}, 1 \mathrm{H}), 4.85(\mathrm{~m}, 1 \mathrm{H}), 4.12-4.07(\mathrm{~m}, 4 \mathrm{H}), 2.0-1.4(\mathrm{~m})$, $1.35-1.30(\mathrm{~m}, 6 \mathrm{H}), 1.29-1.04(\mathrm{~m}), 0.93-0.9(\mathrm{~m}, 6 \mathrm{H}), 0.64$ $(\mathrm{s}, 3 \mathrm{H}) ;{ }^{13} \mathrm{C}$ NMR $\left(100 \mathrm{MHz}, \mathrm{CDCl}_{3}\right) \delta: 160.67,74.39$, $61.49(\mathrm{~d}, J=4.7 \mathrm{~Hz}), 56.48,56.14,41.95,40.50,40.14$, $36.97(\mathrm{~d}, J=16.6 \mathrm{~Hz}), 35.81,35.41,34.97,32.25,28.21$, 26.98, 26.64, 26.28, 26.04 (d, $J=139.2 \mathrm{~Hz}), 24.14,23.25$, 20.83, 19.06, 18.46, 16.37 (d, $J=3.7 \mathrm{~Hz}), 11.98 ;{ }^{31} \mathrm{P}$ NMR $\left(162 \mathrm{MHz}, \mathrm{CDCl}_{3}\right) \delta: 32.24$; LRMS-ESI: calc. for $M+\mathrm{Na}^{+}$: 533.3; obsd. 534.

\subsubsection{General procedure for the synthesis of 23- and} 24-phsophonobile acids

Diethyl phosphonate ester $(0.26 \mathrm{~g}, 0.44 \mathrm{mmol})$ was dissolved in dry dichloromethane $(3 \mathrm{~mL})$ under nitrogen and cooled in an ice-water bath. Iodotrimethylsilane $(0.14 \mathrm{~mL}$, $0.98 \mathrm{mmol}$ ) was added dropwise, while maintaining the temperature $0-5{ }^{\circ} \mathrm{C}$, and then warmed to room temperature. After $24 \mathrm{~h}$, the reaction mixture was evaporated in vacuo and the brownish residue was stirred with aq. $\mathrm{NaOH}$ solution $(4 \mathrm{~mL}$ of $0.8 \mathrm{M}, 3.2 \mathrm{mmol}$ ). After $4 \mathrm{~h}$, the basic solution was acidified with conc. $\mathrm{HCl}$ and the precipitated pale yellow product was crystallized from $\mathrm{MeOH} /$ acetone (1:2) to yield phosphonobile acid as a white solid.

2.1.6.1. $3 \alpha, \quad 7 \alpha, \quad 12 \alpha$-trihydroxy-24-nor-5 $\beta$-cholane-23phosphonic acid (23-PCA, 1). Yield 65\%; mp: $257.4-259^{\circ} \mathrm{C} ; \quad[\alpha]_{\mathrm{D}}^{25}(c) 1.85$ in $\left.\mathrm{MeOH}\right)=+27$; FTIR (KBr): $3426 \mathrm{~cm}^{-1}$ (hydroxyl); ${ }^{1} \mathrm{H}$ NMR (300 MHz, DMSO$\left.\mathrm{d}_{6}\right) \delta: 3.77(\mathrm{~s}, 1 \mathrm{H}), 3.60,(\mathrm{~s}, 1 \mathrm{H}), 3.16(\mathrm{bs}, 1 \mathrm{H}), 1.8-1.13$ (m), $0.91(\mathrm{~d}, J=6 \mathrm{~Hz}, 3 \mathrm{H}), 0.81(\mathrm{~s}, 3 \mathrm{H}), 0.59(\mathrm{~s}, 3 \mathrm{H}) ;{ }^{13} \mathrm{C}$ NMR $(100 \mathrm{MHz}$, DMSO-d 6 ) $\delta: 71.00,70.43,66.26,45.66$, $41.50,41.36,35.79$ (d, $J=15 \mathrm{~Hz}), 35.29,34.84,34.36$, $30.38,28.68,28.52,27.26,26.21,23.99(\mathrm{~d}, J=136 \mathrm{~Hz})$, $22.78,22.60,16.81,12.35 ;{ }^{31}$ P NMR (162 MHz, DMSO-d 6 ) $\delta$ : 29.55; HRMS Q-TOF: calc. for $M+\mathrm{Na}^{+}: 467.2538$; obsd. 467.2505 .

2.1.6.2. $3 \alpha, \quad 12 \alpha$-dihydroxy-24-nor-5 $\beta$-cholane-23-phosphonic acid (23-PDCA, 2). Yield 70\%; mp: $262-263^{\circ} \mathrm{C}$; $[\alpha]_{\mathrm{D}}^{25}(c \quad 1.05$ in $\mathrm{MeOH})=+44$; FTIR $(\mathrm{KBr}): 3400 \mathrm{~cm}^{-1}$ (hydroxyl); ${ }^{1} \mathrm{H}$ NMR $\left(300 \mathrm{MHz}\right.$, DMSO-d $\left.{ }_{6}\right) \delta: 3.77(\mathrm{~s}, 1 \mathrm{H})$, $3.36(\mathrm{~m}, 1 \mathrm{H}), 1.90-1.0(\mathrm{~m}), 0.90(\mathrm{~d}, J=6.0 \mathrm{~Hz}, 3 \mathrm{H}), 0.83$ $(\mathrm{s}, 3 \mathrm{H}), 0.59(\mathrm{~s}, 3 \mathrm{H}) ;{ }^{13} \mathrm{C}$ NMR $(100 \mathrm{MHz}$, DMSO-d 6$) \delta$ : 71.02, 69.95, 47.44, 45.95, 45.76, 41.61, 36.27, 35.72 (d, $J=15 \mathrm{~Hz}), 35.14,33.80,32.93,30.20,28.59,27.16,26.97$, 26.09, 23.99 (d, $J=135 \mathrm{~Hz}), 23.48,23.07,16.79,12.46 ;{ }^{31} \mathrm{P}$ NMR (162 MHz, DMSO-d 6 ) $\delta: 29.63$; HRMS Q-TOF: calc. for $M+\mathrm{Na}^{+}:$451.2589; obsd. 451.2577 .

2.1.6.3. $3 \alpha, \quad 7 \alpha$-dihydroxy-24-nor-5 $\beta$-cholane-23-phosphonic acid (23-PCDCA, 3). Yield 66\%; mp: $226-227^{\circ} \mathrm{C}$; $[\alpha]_{\mathrm{D}}^{25}(c 2.1$ in MeOH$)=+9 ;{ }^{1} \mathrm{H}$ NMR $\left(400 \mathrm{MHz}, \mathrm{DMSO}-\mathrm{d}_{6}\right)$ $\delta: 3.64(\mathrm{~s}, 1 \mathrm{H}), 3.22-3.17(\mathrm{~m}, 1 \mathrm{H}), 1.93-0.98(\mathrm{~m}), 0.89$ $(\mathrm{d}, J=6.4 \mathrm{~Hz}, 3 \mathrm{H}), 0.85(\mathrm{~s}, 3 \mathrm{H}), 0.62(\mathrm{~s}, 3 \mathrm{H}) ;{ }^{13} \mathrm{C} \mathrm{NMR}$

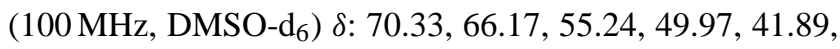
$41.44,35.64$ (d, $J=15.3 \mathrm{~Hz}), 35.31,34.80,34.72,32.30$, $30.54,28.59,27.72,23.91(\mathrm{~d}, J=136.5 \mathrm{~Hz}), 23.12,22.69$, $20.25,18.04,11.69 ;{ }^{31} \mathrm{P}$ NMR $\left(162 \mathrm{MHz}\right.$, DMSO-d $\left._{6}\right) \delta$ : 30.10; HRMS Q-TOF: calc. for $M+\mathrm{Na}^{+}$: 451.2589; obsd. 451.2655 .

2.1.6.4. $3 \alpha, \quad 7 \beta$-dihydroxy-24-nor-5 $\beta$-cholane-23-phosphonic acid (23-PUDCA, 4). Yield 76\%; mp: $234-235^{\circ} \mathrm{C}$; $[\alpha]_{\mathrm{D}}^{25}(c 1.44$ in $\mathrm{MeOH})=+51 ;{ }^{1} \mathrm{H}$ NMR $(400 \mathrm{MHz}$, DMSO$\left.\mathrm{d}_{6}\right) \delta: 3.34-3.26(\mathrm{~m}, 2 \mathrm{H}), 1.96-1.09(\mathrm{~m}), 0.89(\mathrm{~d}, J=4.8 \mathrm{~Hz}$, $3 \mathrm{H}), 0.88(\mathrm{~s}, 3 \mathrm{H}), 0.63(\mathrm{~s}, 3 \mathrm{H}) ;{ }^{13} \mathrm{C}$ NMR $(100 \mathrm{MHz}$, 
DMSO-d 6 ) $\delta: 69.74,69.47,55.83,54.38,49.05,43.02$, $42.18,39.82,38.75,37.67,37.23,35.56(\mathrm{~d}, J=15.2 \mathrm{~Hz})$, $34.82,33.74,30.20,28.67,28.63,28.10,26.63,23.94$ $(\mathrm{d}, J=132.6 \mathrm{~Hz}), 23.28,20.85,18.18,12.07 ;{ }^{31} \mathrm{P} \mathrm{NMR}$ (162 MHz, DMSO-d 6 ) $\delta$ : 29.82; HRMS Q-TOF: calc. for $M+\mathrm{Na}^{+}:$451.2589; obsd. 451.2603.

\subsubsection{3 $\alpha$-hydroxy-24-nor-5 $\beta$-cholane-23-phosphonic} acid (23-PLCA, 5). Yield 75\%; mp: $226.6-229^{\circ} \mathrm{C} ;[\alpha]_{\mathrm{D}}^{25}(c$ 0.65 in $\mathrm{EtOH})=+30$; FTIR $(\mathrm{KBr}): 3418 \mathrm{~cm}^{-1}$ (hydroxyl); ${ }^{1} \mathrm{H}$ NMR (300 MHz, DMSO-d 6 ) $\delta: 3.2-3.17(\mathrm{~m}, 1 \mathrm{H})$, 1.9-1.0 (m), .87 (bs, 6H), $0.63(\mathrm{~s}, 3 \mathrm{H}) ;{ }^{13} \mathrm{C}$ NMR $(75 \mathrm{MHz}$, DMSO-d 6 ) $\delta: 69.90,56.06,55.26,42.26,41.57,36.29$, $35.64(\mathrm{~d}, J=17 \mathrm{~Hz}), 35.44,35.19,34.24,30.39,28.69$, $27.72,26.93,26.21,24.03(\mathrm{~d}, J=136 \mathrm{~Hz}), 23.98,23.31$, 20.45, 18.08, 11.96; ${ }^{31} \mathrm{P}$ NMR (162 MHz, DMSO-d 6$) \delta$ : 29.33; HRMS Q-TOF: calc. for $M+\mathrm{Na}^{+} ; M+\mathrm{K}^{+}$: 435.2640, 451.2331; obsd. 435.2653, 451.2379 .

2.1.6.6. $3 \alpha, 7 \alpha, 12 \alpha$-trihydroxy-5 $\beta$-cholane-24-phosphonic acid (24-PCA, 6). Yield 60\%; mp: $189-190{ }^{\circ} \mathrm{C} ;[\alpha]_{\mathrm{D}}^{24}(c$ 1.68 in $\mathrm{MeOH})=+30 ;{ }^{1} \mathrm{H}$ NMR $(400 \mathrm{MHz}$, DMSO-d 6$) \delta$ : $3.79(\mathrm{~s}, 1 \mathrm{H}), 3.61(\mathrm{~s}, 1 \mathrm{H}), 3.21-3.16(\mathrm{~m}, 1 \mathrm{H}), 2.3-2.11(\mathrm{~m}$, 2H), 2.0-1.1 (m), $0.93(\mathrm{~d}, J=6.4 \mathrm{~Hz}, 3 \mathrm{H}), 0.81(\mathrm{~s}, 3 \mathrm{H})$, 0.59 (s, 3H); ${ }^{13} \mathrm{C}$ NMR (100 MHz, DMSO-d 6 ) $\delta: 70.91$, $70.31,66.20,66.15,45.97,45.59,41.40,41.21,36.65(\mathrm{~d}$, $J=5.6 \mathrm{~Hz}), 35.17,34.95,34.70,34.25,30.25,28.42,27.94$ $(\mathrm{d}, J=134.5 \mathrm{~Hz}), 27.20,26.09,22.62,22.44,19.15,17.12$, 12.16; ${ }^{31} \mathrm{P}$ NMR (162 MHz, DMSO-d 6 ) $\delta: 28.66$; HRMS QTOF: calc. for $M+\mathrm{Na}^{+} ; M+\mathrm{K}^{+}: 481.2695,497.2434$; obsd. 481.2664, 497.2411.

2.1.6.7. $3 \alpha, 12 \alpha$-dihydroxy-5 $\beta$-cholane-24-phosphonic acid (24-PDCA, 7). Yield 55\%; mp: $242-243.5^{\circ} \mathrm{C} ;[\alpha]_{\mathrm{D}}^{24}(c 1.3$ in $\mathrm{MeOH})=+49 ;{ }^{1} \mathrm{H}$ NMR $\left(400 \mathrm{MHz}, \mathrm{DMSO}-\mathrm{d}_{6}\right) \delta: 3.80(\mathrm{~s}$, $1 \mathrm{H}), 3.41-3.34(\mathrm{~m}, 1 \mathrm{H}), 1.85-1.0(\mathrm{~m}), 0.94(\mathrm{~d}, J=6.8 \mathrm{~Hz}$, $3 \mathrm{H}), 0.86(\mathrm{~s}, 3 \mathrm{H}), 0.61(\mathrm{~s}, 3 \mathrm{H}) ;{ }^{13} \mathrm{C}$ NMR (75 MHz, DMSO$\left.\mathrm{d}_{6}\right) \delta: 71.02,69.93,47.48,46.13,45.95,41.62,36.75(\mathrm{~d}$, $J=17.3 \mathrm{~Hz}$ ), 36.29, 35.68, 35.11, 33.84, 32.95, 30.24, 28.11 (d, $J=135.8 \mathrm{~Hz}), 28.66,27.34,27.01,26.13,23.53,23.13$, 19.33, 19.28, 17.24, 12.46; ${ }^{31} \mathrm{P}$ NMR (162 MHz, DMSO$\left.\mathrm{d}_{6}\right) \delta$ : 28.71; HRMS Q-TOF: calc. for $M+\mathrm{Na}^{+} ; M+\mathrm{K}^{+}$: 465.2746, 481.2485; obsd. 465.2740, 481.2447.

2.1.6.8. $3 \alpha, 7 \alpha$-dihydroxy-5 $\beta$-cholane-24-phosphonic acid (24-PCDCA, 8). Yield 75\%; mp: $234-235^{\circ} \mathrm{C} ;[\alpha]_{\mathrm{D}}^{25}(c 1.38$ in $\mathrm{MeOH})=+15 ;{ }^{1} \mathrm{H} \mathrm{NMR}\left(400 \mathrm{MHz}, \mathrm{DMSO}_{-} \mathrm{d}_{6}\right) \delta: 3.61$ (s, 1H), 3.23-3.15 (m, 1H), 1.9-1.0 (m), 0.89 (d, $J=6.4 \mathrm{~Hz}$, $3 \mathrm{H}), 0.83$ (s, 3H), 0.60 (s, 3H); ${ }^{13} \mathrm{C} \mathrm{NMR}$ (100 MHz, DMSO$\left.\mathrm{d}_{6}\right) \delta: 70.20,66.03,55.57,49.86,41.79,41.32,36.53(\mathrm{~d}$, $J=15.8 \mathrm{~Hz}), 35.19,34.89,34.65,34.59,32.15,30.39,27.86$ (d, $J=134.9 \mathrm{~Hz}), 27.72,22.99,22.55,20.12,19.16,18.31$, 11.49; ${ }^{31} \mathrm{P}$ NMR (162 MHz, DMSO-d 6 ) $\delta: 28.58$; HRMS QTOF: calc. for $M+\mathrm{Na}^{+} ; M+\mathrm{K}^{+}: 465.2746,481.2485$; obsd. 465.2729, 481.2477.
2.1.6.9. $3 \alpha$, 7 $\beta$-dihydroxy-5 $\beta$-cholane-24-phosphonic acid (24-PUDCA, 9). Yield 64\%; mp: $182-183{ }^{\circ} \mathrm{C} ;[\alpha]_{\mathrm{D}}^{25}(c 1.7 \mathrm{in}$ $\mathrm{MeOH})=+53 .{ }^{1} \mathrm{H}$ NMR $(400 \mathrm{MHz}$, DMSO-d 6 ) $\delta: 3.36-3.26$ $(\mathrm{m}, 2 \mathrm{H}), 1.9-1.0(\mathrm{~m}), 0.90(\mathrm{~d}, J=6.4 \mathrm{~Hz}, 3 \mathrm{H}), 0.88(\mathrm{~s}$, $3 \mathrm{H}), 0.64(\mathrm{~s}, 3 \mathrm{H}) ;{ }^{13} \mathrm{C}$ NMR $(100 \mathrm{MHz}$, DMSO-d 6$) \delta$ : 69.55, 69.29, 55.73, 54.69, 42.67, 42.03, 38.59, 37.54, 37.12, $36.52(\mathrm{~d}, J=16.1 \mathrm{~Hz}), 34.79,34.69,33.60,30.07,27.83(\mathrm{~d}$, $J=135.9 \mathrm{~Hz}), 28.09,27.15,26.50,23.13,20.69,19.19,18.43$, $11.85 ;{ }^{31} \mathrm{P}$ NMR (162 MHz, DMSO-d 6 ) $\delta: 28.67$; HRMS QTOF: calc. for $M+\mathrm{Na}^{+}$; $M+\mathrm{K}^{+}: 465.2746,481.2485$; obsd. 465.2743, 481.2408.

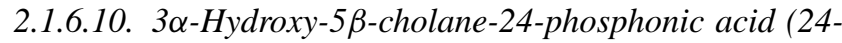
PLCA, 10). Yield 90\%; m. p.: $227-228^{\circ} \mathrm{C} ;[\alpha]_{\mathrm{D}}^{25}(c 1.0$ in $\mathrm{EtOH})=+32 ;{ }^{1} \mathrm{H}$ NMR $\left(400 \mathrm{MHz}, \mathrm{DMSO}_{-} \mathrm{d}_{6}\right) \delta: 3.40-3.35$ $(\mathrm{m}, 1 \mathrm{H}), 1.96-1.0(\mathrm{~m}), 0.89(\mathrm{~d}, J=7.2 \mathrm{~Hz}, 3 \mathrm{H}), 0.88(\mathrm{~s}, 3 \mathrm{H})$, $0.63(\mathrm{~s}, 3 \mathrm{H}) ;{ }^{13} \mathrm{C}$ NMR (100 MHz, DMSO-d 6 ) $\delta: 69.80$, 56.01, 55.65, 42.19, 41.47, $36.52(\mathrm{~d}, J=16.1 \mathrm{~Hz}), 36.18$, $35.33,35.07,34.85,34.12,30.25,27.88(\mathrm{~d}, J=135.5 \mathrm{~Hz})$, 27.71, 26.81, 26.06, 23.73, 23.15, 20.33, 19.24, 18.31, 11.58; ${ }^{31} \mathrm{P}$ NMR (162 MHz, DMSO-d 6 ) $\delta: 28.72$; HRMS Q-TOF: calc. for $M+\mathrm{Na}^{+}:$449.2797; obsd. 449.2791.

\subsubsection{Estimation of solubilized cholesterol by enzymatic assay}

The amount of solubilized cholesterol was estimated by an enzymatic assay [13]. Samples were incubated with a commercially available cholesterol reagent [14] at $37^{\circ} \mathrm{C}$ for $10 \mathrm{~min}$, and then absorbance was recorded at $510 \mathrm{~nm}$. The cholesterol converted was estimated by comparing this absorbance with that from a standard sample.

\section{Results and discussion}

\subsection{Synthesis}

The syntheses of 23-phosphonobile acids were accomplished as shown in Scheme 1. In addition, the onecarbon homologs were also synthesized starting from bile acids (Scheme 2). Cholic acid (CA), deoxycholic acid (DCA), chenodeoxycholic acid (CDCA), ursodeoxycholic acid (UDCA) and lithocholic acid (LCA) were converted to their corresponding performyl derivatives by heating with formic acid.

For the syntheses of 23-phosphonobile acids, formyl protected bile acids were subjected to a modified Hunsdiecker reaction (iododecarboxylation) in the presence of $\mathrm{Pb}(\mathrm{OAc})_{4} / \mathrm{I}_{2} / h v$ to yield the corresponding formylated $24-$ nor-23-iodo derivatives. The iodo derivatives were refluxed with triethyl phosphite at $160^{\circ} \mathrm{C}$ under nitrogen (Arbuzov reaction) to furnish the corresponding formylated diethyl phosphonocholanate esters. The cleavage of the ethyl groups was achieved by stirring with $\mathrm{Me}_{3} \mathrm{SiI}$ in $\mathrm{CH}_{2} \mathrm{Cl}_{2}$ at $\mathrm{rt}$. The removal of the TMS ester and the formyl groups were effected in the same pot by alkaline hydrolysis in $\mathrm{MeOH}$. The basic solution 


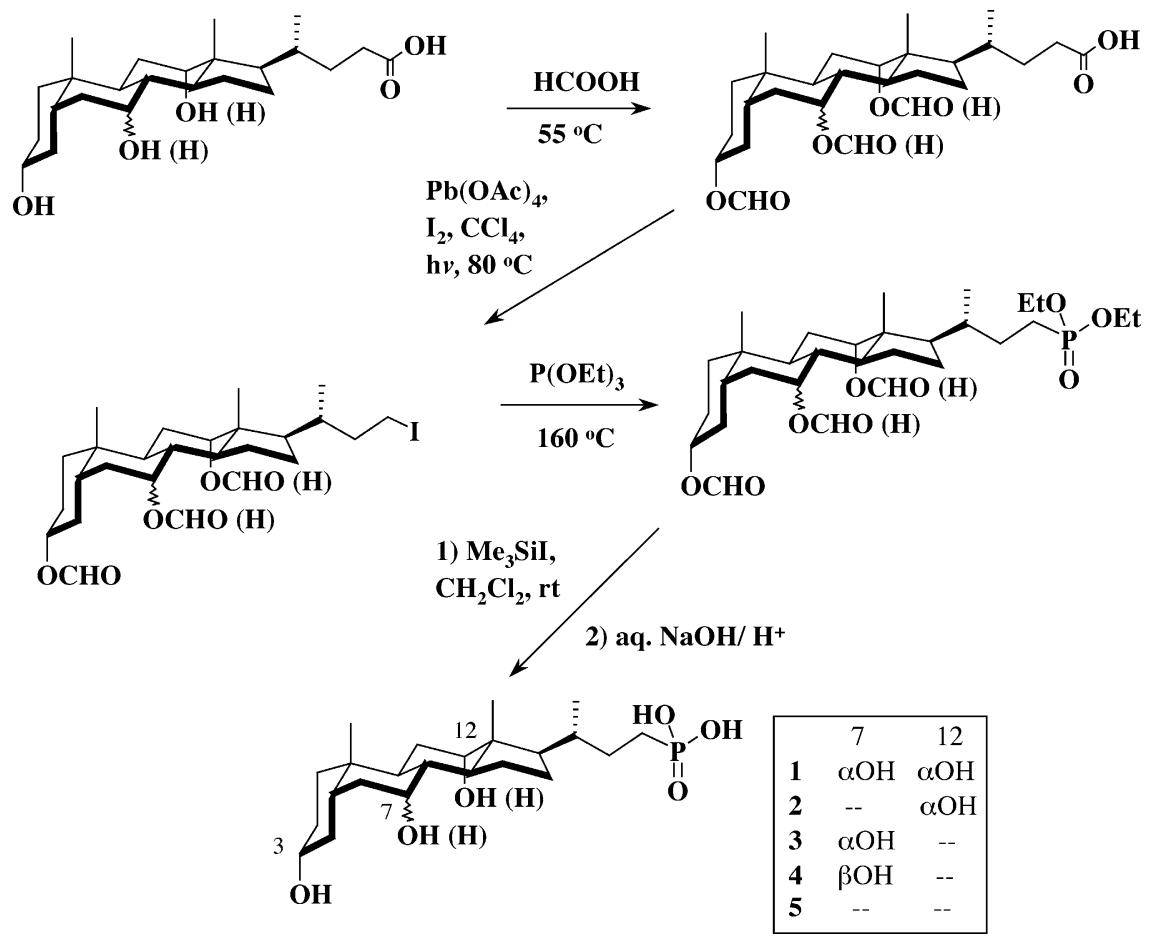

Scheme 1.

containing phosphonobile salt was neutralized $(\mathrm{pH} \sim 1)$ and filtered to yield the 23-phosphonobile acids.

For the synthesis of 24-phosphonobile acids, the formylated bile acids were reduced to the corresponding formyl protected alcohols in two steps. First a mixed anhydride was made with ethyl chloroformate in the presence of triethy- lamine, which was then selectively reduced by $\mathrm{NaBH}_{4}$ in $\mathrm{MeOH}$. The 24-hydroxy compounds were converted to the corresponding 24-iodo derivatives using $\mathrm{PPh}_{3} / \mathrm{I}_{2} /$ imidazole in dichloromethane at $\mathrm{rt}$ [15]. The formation of diethyl esters of 24-phosphonobile acids and subsequent deprotection of ethyl and formyl groups were accomplished following
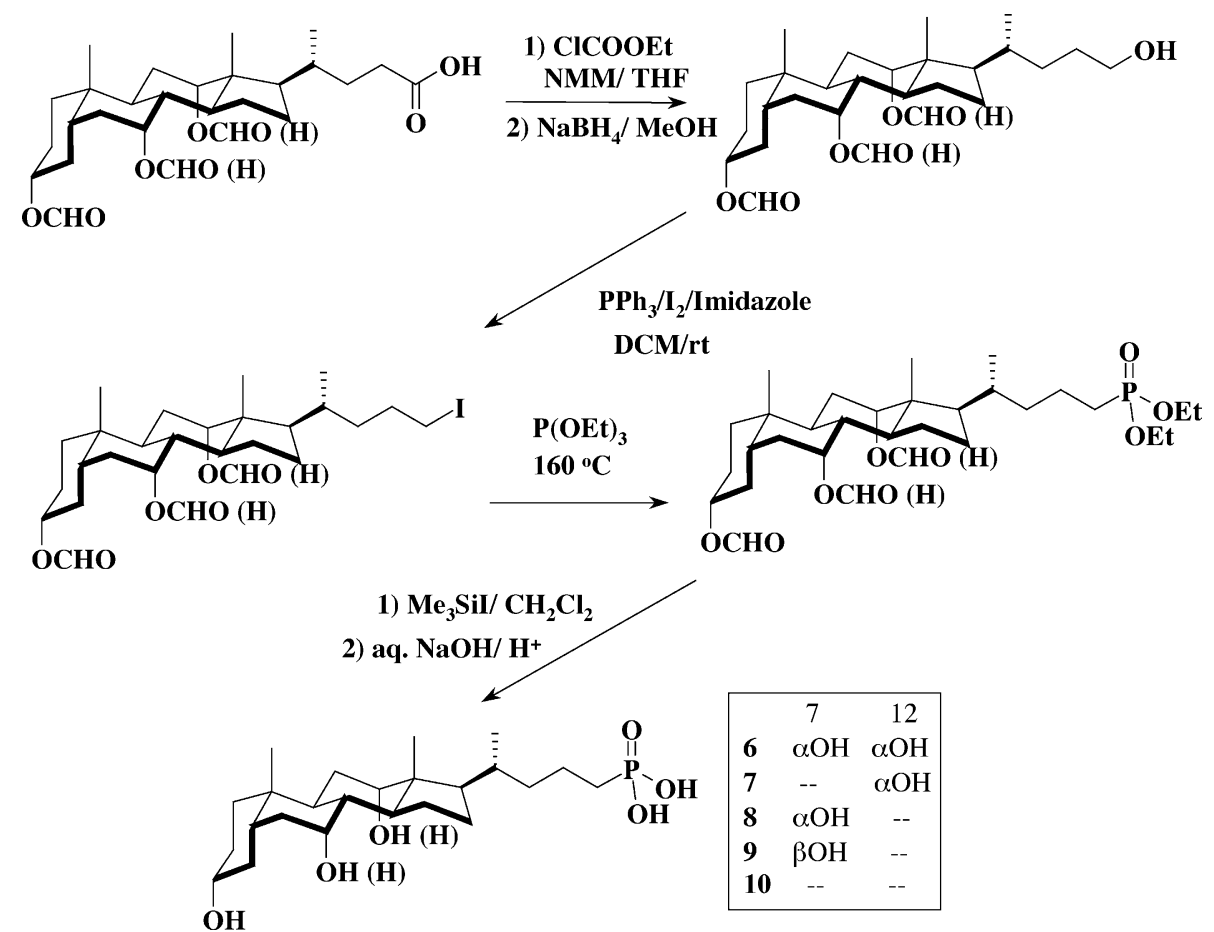

Scheme 2. 


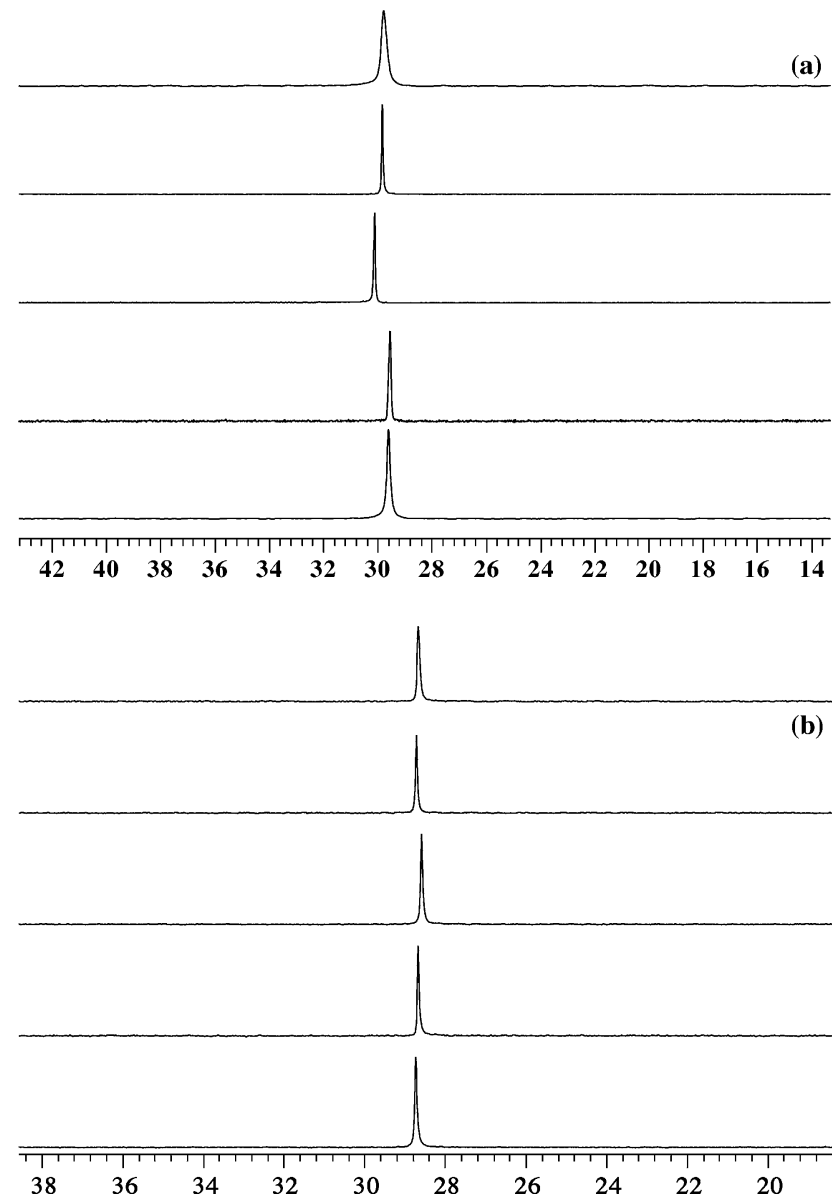

Fig. $1 .{ }^{31} \mathrm{P}$ NMR spectra of 23-PBA (a) and 24-PBA (b) in DMSO-d 6 (162 MHz). Top to bottom: phosphonocholic, phosphonodeoxycholic, phosphonochenodeoxycholic, phosphonoursodeoxycholic and phosphonolithocholic acid.

the same procedures as described for 23-phosphonobile acids. All the compounds synthesized were characterized spectroscopically. The ${ }^{31} \mathrm{P}$ NMR spectra of $23-$ and 24-phosphonobile acids are shown in Fig. 1.

\subsection{In vitro equilibrium cholesterol solubilization by 23- and 24-PBSs}

All the equilibrium cholesterol solubilization experiments were done at $37^{\circ} \mathrm{C}$ in solutions containing varying concentrations of disodium salt of phosphonobile acids and $0.15 \mathrm{M}$ $\mathrm{NaCl}$ in $\mathrm{pH} 6.4$ (0.1 M phosphate) buffer solutions. The solubilized cholesterol was analyzed using an enzymatic assay (see Section 2). The equilibrium cholesterol solubility data for 23- and 24-phosphonobile salts at pH 6.4 (0.1 M potassium phosphate), where the phosphonobile acids are predominantly monoionic, are presented in Table 1 . In general, the equilibrium solubilizing power (Sp), defined as the ratio of cholesterol:PBS, is slightly higher for 24-PBSs than that of 23-PBSs with the solubilizing power of the corresponding bile salts (at $\mathrm{pH} 10.0)[16,17]$ being in between. The equilibrium solubility of cholesterol is greatly influenced by the
Table 1

Comparison of cholesterol sloubilization efficiency of 23- and 24-PBSs with those of bile salts

\begin{tabular}{lllll}
\hline Entry & $\begin{array}{l}\text { PBS (50 mM) in pH 6.4 (0.1 M } \\
\text { phosphate buffer), 0.15 M } \\
\text { NaCl at } 37^{\circ} \mathrm{C}\end{array}$ & $\begin{array}{l}\text { Ratio of cholesterol:bile } \\
\text { salt (Sp) }\end{array}$ \\
\cline { 3 - 5 } & 23-PBS & 24-PBS & BS $^{\mathrm{b}}$ \\
\hline 1 & PC & $1: 46(\mathbf{1})$ & $1: 23(\mathbf{6})$ & $1: 29$ \\
2 & PDC & $1: 19(\mathbf{2})$ & $1: 13.5(\mathbf{7})$ & $1: 15.6$ \\
3 & PCDC & $1: 20(\mathbf{3})$ & $\mathbf{( 8 )}^{\mathrm{c}}$ & $1: 14$ \\
4 & PUDC & $1: 238(\mathbf{4})$ & $1: 151(\mathbf{9})$ & $1: 364$ \\
\hline
\end{tabular}

${ }^{a}$ Molar concentration of dissolved cholesterol $=0.05 \times \mathrm{Sp}$; the lithocholate analogs $(\mathbf{5}$ and $\mathbf{1 0})$ were insoluble under identical conditions.

${ }^{b}$ The values are taken from ref. [17] at $\mathrm{pH} 10$.

${ }^{c}$ Under the experimental conditions, a turbid gel was obtained, so the amount of solubilized cholesterol could not be measured.

structure and number of hydroxyl groups present in the PBSs. For both 23- and 24-PBSs, the solubilizing power decreases in the following order: $\mathrm{PDC} \cong \mathrm{PCDC}>\mathrm{PC} \gg \mathrm{PUDC}$. The same trend of cholesterol solubilization is observed for bile salts, which correlated inversely with hydrophilicity [18]. Interestingly, the 23- and 24-PUDC showed 1.5 and 2.4 times higher solubilization, respectively, compared to that of UDC. Kinetic experiments show a fast initial rate of solubilization, which slows down with time. For 23-PCDC, cholesterol solubilization saturates in about $8 \mathrm{~h}$.

\subsection{Effect of pH on equilibrium cholesterol solubility}

The effect of $\mathrm{pH}$ on the equilibrium cholesterol solubility was examined using 23-PCDC and 23-PUDC as the solubilizing agents. The solubilization experiments were done in three different buffer solutions $(0.1 \mathrm{M})$ : $\mathrm{pH} 6.4$ (phosphate), 7.4 (TRIS) and 10.0 (carbonate) and $0.15 \mathrm{M} \mathrm{NaCl}$. The equilibrium cholesterol solubility decreases considerably upon increasing the bulk $\mathrm{pH}$. The same trend was observed for phosphonocheno and phosphonoursodeoxycholates (Fig. 2). An increase in the bulk pH increases the CMC of phospho-

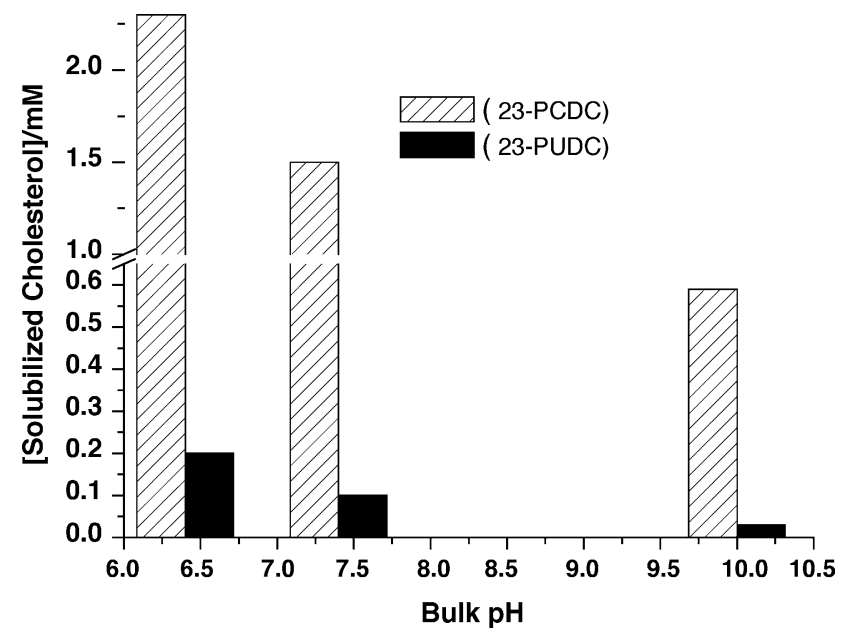

Fig. 2. Amount of solubilized cholesterol (by 23-PCDC and 23-PUDC, $50 \mathrm{mM}$ ) as a function of pH 6.4 (phosphate), 7.4 (TRIS) and 10.0 (carbonate). 
nobile salts. For example, the CMC of 23-PCDC increased from $2 \mathrm{mM}$ to $7-8 \mathrm{mM}$ when the $\mathrm{pH}$ is changed from 6.4 to 10. Hence, the observed decrease in equilibrium solubility is possibly due to an increase in the $\mathrm{CMC}$, which decreases the number of micelles formed at a given total concentration of the bile salt.

\section{Conclusions}

We synthesized a new class of bile acid analogs. In vitro cholesterol solubilizing efficiency of 23- and 24phosphonobile salts has been studied. The 24-PBSs solubilize cholesterol slightly better than 23-PBSs and bile salts. We believe that our preliminary results are encouraging to further explore a better medicinal therapy for cholesterol gallstone dissolution. The aggregation and gelation properties of these new compounds will be published elsewhere.

\section{Acknowledgments}

We thank the Jawaharlal Nehru Centre for Advanced Scientific Research, Bangalore for financial support of this work. Ponnusamy Babu thanks CSIR for fellowship.

\section{References}

[1] Carey MC. Physical-chemical properties of bile acids and their salts. In: Danielsson H, Sjövall J, editors. Sterols and bile acids. Amsterdam: Elsevier; 1985. p. 345-403.

[2] Borgström B, Barrowman JA, Lindström M. Roles of bile acids in intestinal lipid digestion and adsorption. In: Danielsson H, Sjövall J, editors. Sterols and bile acids. Amsterdam: Elsevier; 1985. p. 405-25.

[3] Hofmann AF. Bile acid science (cholanology) at the dawn of a new millennium: past progress and challenges for the future. In: Northfield TC, Ahmed HA, Jazrawl RP, Zentler-Munro PL, editors. Bile acids in hepatobiliary disease. Dordrecht: Kluwer Academic Publications; 1999. p. 303-32.

[4] Carey MC. Formation and growth of cholesterol gallstones: the new synthesis. In: Fromm H, Leuschner U, editors. Bile acids - cholesta- sis - gallstones. Advances in basic and clinical bile acid research. Dordrecht: Kluwer Academic Publications; 1996. p. 147-75.

[5] Schoenfield LJ, Lachin JM. Chenodiol (chenodeoxycholic acid) for dissolution of gallstones: the National Cooperative Gallstone Study. A controlled trial of efficacy and safety. Ann Intern Med 1981;95:257-82.

[6] Paumgartner G, Pauletzki J, Sackmann M. Ursodeoxycholic acid treatment of cholesterol gallstone disease. Scand J Gastroenterol 1994;29:27-31.

[7] Lillienau J, Schteingart CD, Hofmann AF. Physicochemical and physiological properties of cholylsarcosine. A potential replacement detergent for bile acid deficiency states in the small intestine. J Clin Invest 1992;89:420-31.

[8] Kuroki S, Une M, Mosbach EH. Synthesis of potential cholelitholytic

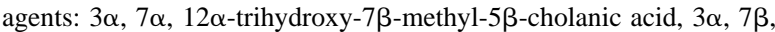
$12 \alpha$-trihydroxy- $7 \alpha$-methyl- $5 \beta$-cholanic acid, $3 \alpha, 12 \alpha$-dihydroxy- $7 \varepsilon$ methyl-5 $\beta$-cholanic acid. J Lipid Res 1985;26:1205-11.

[9] Kihira K, Mikami T, Ikawa S, Okamoto A, Yoshii M, Miki S, Mosbach EH, Hoshita T. Synthesis of sulfonate analogs of bile acids. Steroids 1992;57:193-8.

[10] Mikami T, Kihira K, Ikawa S, Yoshii M, Miki S, Mosbach EF, Hoshita T. Metabolism of sulfonate analogs of ursodeoxycholic acid and their effects on biliary bile acid composition in hamsters. J Lipid Res 1993;34:429-35.

[11] Maitra U, Babu P. First Synthesis of phosphonobile acids and preliminary studies on their aggregation properties. Steroids 2003;68:459-63.

[12] Cortese F, Bauman L. Synthesis of conjugated bile acids. II. Glycodesoxycholic acid. J Biol Chem 1936;113:779-85.

[13] (a) Tarbutton PN, Gunter CR. Clin Chem 1974;20:724; (b) Richmond W. Clin Chem 1973;19:1350.

[14] Accurex, Biomedical Pvt. Ltd., Mumbai. The cholesterol reagent contains a mixture of cholesterol esterase, cholesterol oxidase, peroxidase, 4-aminoantipyrine and phenol in $\mathrm{pH} 6.8$ buffer solution.

[15] Garegg PJ, Samuelsson BJ. Novel reagent system for converting a hydroxy-group into an iodo-group in carbohydrates with inversion of configuration. J Chem Soc Perkin Trans 1980;1:2866.

[16] Carey MC, Montet J-C, Philiphs MC, Armstrong MJ, Mazer NA. Thermodynamic and molecular basis for dissimilar cholesterolsolubilizing capacities by micellar solutions of bile salts: cases of sodium chenodeoxycholate and sodium ursodeoxycholate and their glycine and taurine conjugates. Biochemistry 1981;20:3637-48.

[17] Matsuoka K, Kuranaga Y, Moroi Y. Solubilization of cholesterol and polycyclic aromatic compounds into sodium bile salt micelles (Part 2). Biochim Biophys Acta 2002;1580:200-14.

[18] Armstrong MJ, Carey MC. The hydrophobic-hydrophilic balance of bile salts. Inverse correlation between reverse-phase high performance liquid chromatographic mobilities and micellar cholesterolsolubilizing capacities. J Lipid Res 1982;23:70-80. 